\title{
A Randomized Trial of Progesterone in Women with Bleeding in Early Pregnancy
}

\author{
A. Coomarasamy, A.J. Devall, V. Cheed, H. Harb, L.J. Middleton, I.D. Gallos, \\ H. Williams, A.K. Eapen, T. Roberts, C.C. Ogwulu, I. Goranitis, J.P. Daniels, \\ A. Ahmed, R. Bender-Atik, K. Bhatia, C. Bottomley, J. Brewin, M. Choudhary, \\ F. Crosfill, S. Deb, W.C. Duncan, A. Ewer, K. Hinshaw, T. Holland, F. Izzat, \\ J. Johns, K. Kriedt, M.-A. Lumsden, P. Manda, J.E. Norman, N. Nunes, \\ C.E. Overton, S. Quenby, S. Rao, J. Ross, A. Shahid, M. Underwood, \\ N. Vaithilingam, L. Watkins, C. Wykes, A. Horne, and D. Jurkovic
}

\section{A BSTRACT}

\section{BACKGROUND}

Bleeding in early pregnancy is strongly associated with pregnancy loss. Progesterone is essential for the maintenance of pregnancy. Several small trials have suggested that progesterone therapy may improve pregnancy outcomes in women who have bleeding in early pregnancy.

\section{METHODS}

We conducted a multicenter, randomized, double-blind, placebo-controlled trial to evaluate progesterone, as compared with placebo, in women with vaginal bleeding in early pregnancy. Women were randomly assigned to receive vaginal suppositories containing either $400 \mathrm{mg}$ of progesterone or matching placebo twice daily, from the time at which they presented with bleeding through 16 weeks of gestation. The primary outcome was the birth of a live-born baby after at least 34 weeks of gestation. The primary analysis was performed in all participants for whom data on the primary outcome were available. A sensitivity analysis of the primary outcome that included all the participants was performed with the use of multiple imputation to account for missing data.

\section{RESULTS}

A total of 4153 women, recruited at 48 hospitals in the United Kingdom, were randomly assigned to receive progesterone (2079 women) or placebo (2074 women). The percentage of women with available data for the primary outcome was $97 \%$ (4038 of 4153 women). The incidence of live births after at least 34 weeks of gestation was $75 \%$ ( 1513 of 2025 women) in the progesterone group and 72\% (1459 of 2013 women) in the placebo group (relative rate, 1.03; 95\% confidence interval [CI], 1.00 to $1.07 ; \mathrm{P}=0.08$ ). The sensitivity analysis, in which missing primary outcome data were imputed, resulted in a similar finding (relative rate, 1.03; 95\% $\mathrm{CI}, 1.00$ to $1.07 ; \mathrm{P}=0.08$ ). The incidence of adverse events did not differ significantly between the groups.

\section{CONCLUSIONS}

Among women with bleeding in early pregnancy, progesterone therapy administered during the first trimester did not result in a significantly higher incidence of live births than placebo. (Funded by the United Kingdom National Institute for Health Research Health Technology Assessment program; PRISM Current Controlled Trials number, ISRCTN14163439.)

The authors' full names, academic degrees, and affiliations are listed in the Appendix. Address reprint requests to Dr. Coomarasamy at the Institute of Metabolism and Systems Research, College of Medical and Dental Sciences, University of Birmingham Edgbaston, Birmingham B15 2TT, United Kingdom, or at a.coomarasamy@bham.ac.uk.

N Engl J Med 2019;380:1815-24. DOI: 10.1056/NEJMoa1813730

Copyright (C) 2019 Massachusetts Medical Society. 
M ISCARRIAGE AFFECTS ONE IN FIVE pregnancies. ${ }^{1}$ Miscarriage can cause excessive bleeding, infection, and complications associated with surgical treatment, ${ }^{2}$ as well as substantial psychological harm, including anxiety, depression, and post-traumatic stress disorder. ${ }^{3,4}$

Progesterone, which is produced by the corpus luteum in the ovary, is necessary to prepare the endometrium for implantation of the embryo and thus is an essential hormone for a successful pregnancy. Additional progesterone is produced when an embryo implants in the endometrium and during early placental development. Subsequently, beginning at approximately 12 weeks of pregnancy, the placenta becomes the dominant source of progesterone. ${ }^{5}$

The physiological importance of progesterone has prompted researchers, physicians, and patients to consider progesterone supplementation during early pregnancy to prevent miscarriages. Progesterone supplementation in early pregnancy has been attempted in two contexts: the first is to prevent miscarriages in asymptomatic women who have a history of recurrent miscarriages, and the second is to rescue a pregnancy in women who have started to bleed during early pregnancy. ${ }^{6}$ We addressed the first scenario in a previous issue of the Journal and found no beneficial effect of progesterone in women with a history of unexplained recurrent miscarriages. The current trial focuses on women with vaginal bleeding in early pregnancy.

A Cochrane review (originally published in 2007 and last updated in 2018) ${ }^{6}$ of 7 randomized trials of progestational agents that involved women with bleeding in early pregnancy showed a significantly lower risk of miscarriages among women who received progesterone than among those who received placebo or no treatment (odds ratio, 0.64; 95\% confidence interval [CI], 0.47 to 0.87 ) but noted that the trials were small (the largest trial had a sample size of 191) and had methodologic weaknesses. Another Cochrane review of 13 trials of progestational agents that involved women with recurrent miscarriages was originally published in 2003 and was last updated in 2018. ${ }^{8}$ The American College of Obstetricians and Gynecologists reviewed the evidence and concluded, "For threatened early pregnancy loss, the use of progestins is controversial, and conclusive evidence supporting their use is lack- ing. Women who have experienced at least three prior pregnancy losses, however, may benefit from progesterone therapy in the first trimester." $\mathrm{We}$ conducted the multicenter, randomized, parallelgroup, double-blind, placebo-controlled PRISM (Progesterone in Spontaneous Miscarriage) trial to investigate whether treatment with progesterone would result in a higher incidence of live births among women with bleeding in early pregnancy than placebo.

\section{METHODS}

TRIAL OVERSIGHT

The PRISM trial was approved by the United Kingdom Medicines and Healthcare Products Regulatory Agency, the United Kingdom National Research Ethics Service Committee (South Central Oxford), and the National Health Service research and development department at each participating hospital. The trial was conducted at clinics that are part of the trial research network of the Tommy's National Centre for Miscarriage Research, which is funded by Tommy's Charity. Progesterone and placebo were purchased from Besins Healthcare. This company had no role in the design of the trial; in the collection, analysis, or interpretation of the data; or in the preparation of the manuscript. Trial oversight and monitoring were provided by a trial steering committee and by an independent data and safety monitoring committee. The first, second, and last authors vouch for the accuracy and completeness of the data and analyses and for the fidelity of the trial to the protocol, available with the full text of this article at NEJM.org.

\section{TRIAL PARTICIPANTS}

The participants in the PRISM trial were recruited at 48 hospitals in the United Kingdom. Women were eligible for enrollment in the trial if they were 16 to 39 years of age, if they had completed less than 12 weeks of pregnancy, if they presented with vaginal bleeding, and if they had an intrauterine gestational sac that was visible on ultrasonography. The upper threshold of 39 years for maternal age was chosen because the probability of miscarriages due to chromosomal abnormalities increases with advancing age, ${ }^{10}$ and progesterone treatment could not be expected to prevent such miscarriages. Participants were excluded if at the time of presenta- 
tion the fetal crown-rump length was $7 \mathrm{~mm}$ or longer with no visible heartbeat; if the gestational sac was a mean of $25 \mathrm{~mm}$ or greater in diameter with no visible fetal pole on ultrasonography; if they had evidence of ectopic pregnancy; if they had life-threatening bleeding; if they had current or recent use of progesterone supplementation; if they had contraindications to progesterone therapy (i.e., a history of liver tumors; current genital or breast cancer, severe arterial disease, or acute porphyria; or a history during pregnancy of idiopathic jaundice, severe pruritus, or pemphigoid gestationis); or if they were participating in any other blinded, placebocontrolled trials of medicinal products in pregnancy. All the participants provided written informed consent.

\section{TRIAL ASSIGNMENTS}

Participants were randomly assigned, in a 1:1 ratio, to administer to themselves vaginal suppositories containing either $400 \mathrm{mg}$ of micronized progesterone (Utrogestan, Besins Healthcare) or matching placebo twice daily, from the time of randomization through 16 completed weeks of gestation (or earlier if pregnancy ended before 16 weeks). If vaginal administration was not preferred, participants could administer the suppositories rectally. Randomization was performed through a secure, centralized Internet facility with the use of minimization to balance the trial-group assignments according to maternal age ( $<35$ years vs. $\geq 35$ years), body-mass index (BMI [the weight in kilograms divided by the square of the height in meters], $<30$ vs. $\geq 30$ ), fetal heart activity (present vs. absent), estimated gestation at presentation ( $<42$ days vs. $\geq 42$ days), and amount of vaginal bleeding (pictorial bloodloss assessment chart [PBAC] score of $\leq 2$ vs. score of $\geq 3$; scores range from 1 to 4 , with higher scores indicating greater vaginal blood loss). ${ }^{11}$ The appearance, route, and timing of administration of progesterone and placebo were identical. Participants, physicians, and trial nurses were unaware of the trial-group assignments throughout the course of the trial.

\section{OUTCOME MEASURES}

The primary outcome was the birth of a liveborn baby after at least 34 completed weeks of gestation. Secondary outcomes included the time from conception to the end date of pregnancy, ongoing pregnancy at 12 weeks of gestation, miscarriage (defined as loss of pregnancy before 24 weeks of gestation), live birth before 34 weeks of gestation, ectopic pregnancy, stillbirth (defined as intrauterine death after at least 24 weeks of gestation), termination of pregnancy, the week of gestation at delivery, birth weight, size (small or large) for gestational age, preeclampsia, Apgar scores, survival at 28 days of neonatal life, and congenital abnormalities, as well as other antenatal, intrapartum, postpartum, and neonatal outcomes. A detailed list of all secondary outcomes is provided in the Supplementary Appendix, available at NEJM.org. We attempted to collect outcome data for all participants who underwent randomization, regardless of adherence to the trial-group assignment.

\section{STATISTICAL ANALYSIS}

We calculated that 1972 women would need to be included in each trial group to provide $90 \%$ power to detect a minimally important absolute difference of 5 percentage points between the progesterone group and the placebo group in the incidence of live births after at least 34 weeks of gestation (65\% vs. $60 \%$ ), at a two-sided alpha level of 0.05 . This minimally important difference was chosen on the basis of a national survey of clinical practitioners in the United Kingdom. We planned to include 4150 women in the trial to account for an expected 5\% loss to follow-up.

The analysis of the primary outcome was performed according to the intention-to-treat principle; a main analysis of all available data was supplemented by a sensitivity analysis of the primary outcome that included all participants and took into account any missing data with the use of multiple imputation..$^{12}$ A Poisson regression model with robust standard errors was used to estimate the relative rates and corresponding 95\% two-sided confidence intervals, with adjustment for the minimization variables. This method has been shown to be appropriate and to be less prone to convergence issues than other similar methods. ${ }^{13}$

For the primary outcome, a P value was generated with the use of a two-sided chi-square test. The statistical analysis plan did not include a provision for correction for multiplicity when the analyses of the secondary outcomes were performed. Therefore, the results are reported as point estimates and $95 \%$ confidence intervals, 
without P values. For continuous outcomes, a linear regression model was used to estimate mean differences, with the same adjustment that was used in the analysis of the primary outcome. The widths of the confidence intervals were not adjusted for multiplicity, so the intervals should not be used to infer definitive treatment effects.

We analyzed the treatment effect on the primary outcome in prespecified subgroups defined according to maternal age ( $<35$ years vs. $\geq 35$ years), BMI ( $<30$ vs. $\geq 30$ ), fetal heart activity (present vs. absent), estimated gestation at presentation ( $<6$ weeks vs. 6 to $<9$ weeks vs. $\geq 9$ weeks), amount of vaginal bleeding (PBAC score of $\leq 2$ vs. score of $\geq 3),{ }^{11}$ number of previous miscarriages ( 0 vs. 1 or 2 vs. $\geq 3$ ), number of gestational sacs ( 1 vs. $\geq 2$ ), race (white, black, south Asian, or other), history of polycystic ovaries (yes vs. no), and previous cervical excision (yes vs. no). The effects of these subgroups were examined by adding the variables for the interaction of subgroup with trial group to the regression model; a chi-square test was used to determine whether the effects of progesterone and placebo differed in the various subgroups.

Interim analyses of principal safety and effectiveness outcomes were performed on behalf of the data and safety monitoring committee by the trial statistician (who remained unaware of the treatment assignments) on two occasions. Because these analyses were performed with the use of the Peto principle, ${ }^{14}$ no adjustment was made in the final $\mathrm{P}$ values to determine significance.

\section{RESULTS}

\section{TRIAL PARTICIPANTS}

From May 19, 2015, through July 27, 2017, a total of 12,862 women were identified as being eligible for the PRISM trial; of these women, 4153 were randomly assigned to receive either progesterone (2079 women) or placebo (2074 women) (Fig. 1). The percentage of women with available data for the primary outcome was 97\% (4038 of 4153 women). Demographic and baseline characteristics were similar in the two trial groups (Table 1, and Table S1 in the Supplementary Appendix). Information on the route of administration was available for $88 \%$ (3662 of 4153) of the women: 99\% (3611 of 3662 women) administered the suppositories vaginally and 1\% (51 of 3662 women) administered them rectally.

\section{OUTCOMES}

The incidence of live births after at least 34 weeks of gestation was $75 \%$ (1513 of 2025 women) in the progesterone group and 72\% (1459 of 2013 women) in the placebo group (relative rate, 1.03; $95 \% \mathrm{CI}, 1.00$ to $1.07 ; \mathrm{P}=0.08$ ). The sensitivity analysis, in which multiple imputation was used for missing data, did not change the findings (relative rate, $1.03 ; 95 \% \mathrm{CI}, 1.00$ to $1.07 ; \mathrm{P}=0.08$ ).

The incidence of ongoing pregnancy at 12 weeks was $83 \%$ (1672 of 2025 women) in the progesterone group and 80\% (1602 of 2013 women) in the placebo group (relative rate, 1.04; $95 \% \mathrm{CI}, 1.01$ to 1.07$)$. The incidence of miscarriage was $20 \%$ (410 of 2025 women) in the progesterone group and 22\% (451 of 2013 women) in the placebo group (relative rate, $0.91 ; 95 \% \mathrm{CI}$, 0.81 to 1.01). The results of all the other secondary outcomes are presented in Table 2, and in Table S2 in the Supplementary Appendix.

A significant subgroup effect was identified for only 1 of the 10 prespecified subgroups the subgroup of participants defined according to the number of previous miscarriages. The incidence of live births in the subgroup of women who had no previous miscarriages was $74 \%$ in the progesterone group and $75 \%$ in the placebo group (relative rate, 0.99 ; 95\% CI, 0.95 to 1.04 ); the incidence among women who had one or two previous miscarriages was $76 \%$ and $72 \%$, respectively (relative rate 1.05; 95\% CI, 1.00 to 1.12); and the incidence among women who had three or more previous miscarriages was $72 \%$ and $57 \%$, respectively (relative rate, 1.28; $95 \%$ CI, 1.08 to 1.51) ( $\mathrm{P}=0.007$ for the interaction between trial group and the number of miscarriages) (Fig. 2). The results of two post hoc subgroup analyses in which we categorized the number of previous miscarriages differently from the subgroup analysis described here are provided in Figure S1 in the Supplementary Appendix.

There was no significant between-group difference in the percentage of participants who had either a maternal or neonatal serious adverse event (5\% [105 of 2025 participants] in the progesterone group and 5\% [98 of 2013 participants] in the placebo group), including specifically the percentage of babies who had neonatal congenital abnormalities (3.4\% in each group), 


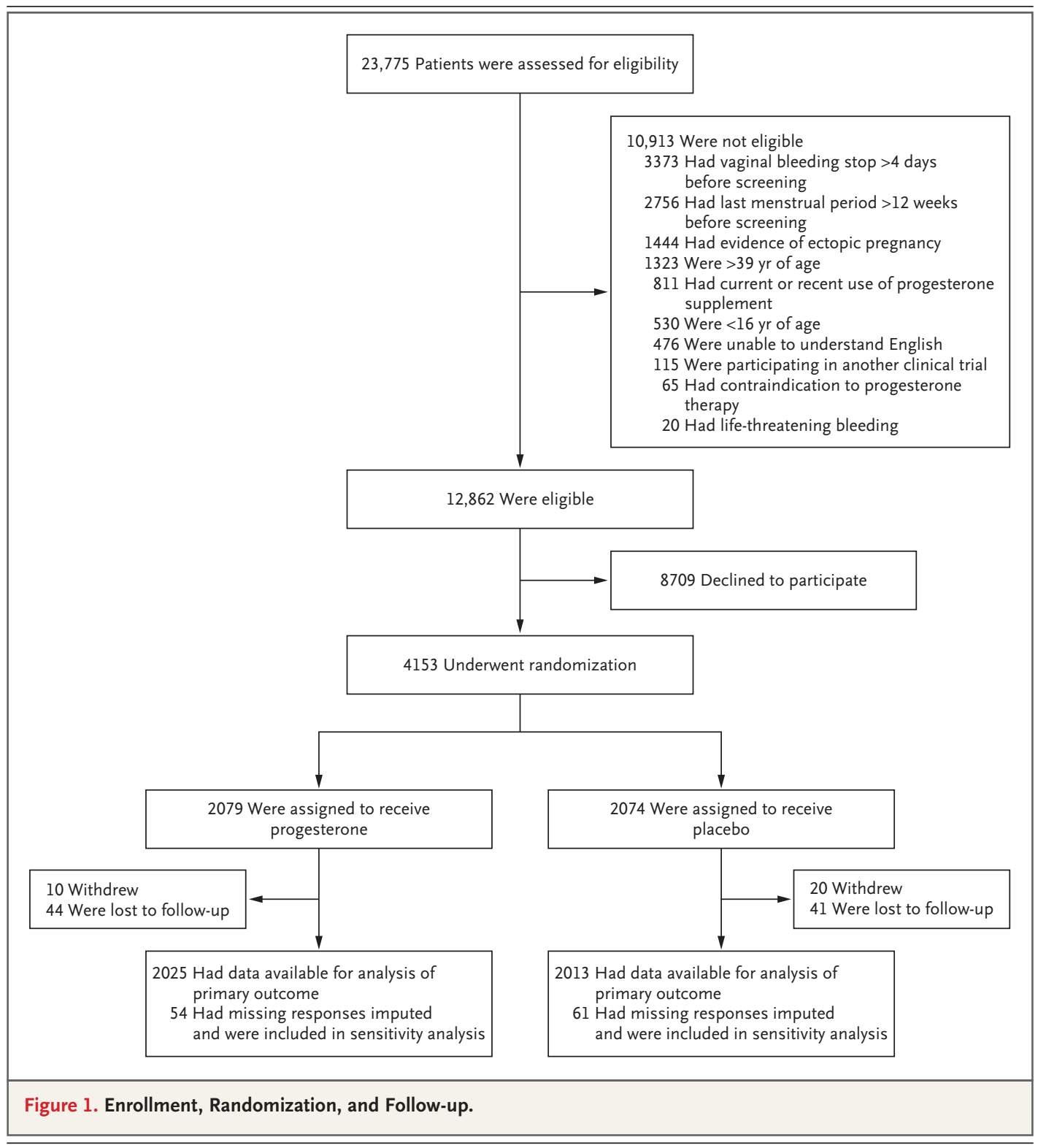

nor was there any significant between-group difference in the number of maternal or neonatal serious adverse events. A summary of serious adverse events is provided in Table S3 in the Supplementary Appendix.

\section{DISCUSSION}

Our large multicenter, randomized, double-blind, placebo-controlled trial showed that among women with bleeding in early pregnancy, progesterone therapy administered during the first trimester of pregnancy did not result in a signifi- cantly higher incidence of live births after at least 34 weeks of gestation than placebo. There was also no significant difference between the groups in the incidence of miscarriage or stillbirth. Although there appeared to be slightly more ongoing pregnancies at 12 weeks in the progesterone group than in the placebo group, an inference of benefit cannot be drawn because the confidence interval for the relative rate was not adjusted for multiplicity of testing.

The large sample size in our trial allowed investigation of the primary outcome in prespecified subgroups. Among the 10 subgroup analyses, 


\begin{tabular}{|c|c|c|}
\hline Characteristic & $\begin{array}{l}\text { Progesterone } \\
(\mathrm{N}=\mathbf{2 0 7 9})\end{array}$ & $\begin{array}{l}\text { Placebo } \\
(\mathrm{N}=\mathbf{2 0 7 4})\end{array}$ \\
\hline \multicolumn{3}{|l|}{ Demographic characteristics } \\
\hline \multicolumn{3}{|l|}{ Maternal age } \\
\hline Mean - yr & $30.6 \pm 5.1$ & $30.5 \pm 5.1$ \\
\hline \multicolumn{3}{|l|}{ Distribution — no. (\%) } \\
\hline$<35 \mathrm{yr}$ & $1604(77)$ & 1601 (77) \\
\hline$\geq 35 \mathrm{yr}$ & $475(23)$ & $473(23)$ \\
\hline \multicolumn{3}{|l|}{ Body-mass index'َ } \\
\hline Mean & $26.4 \pm 6.2$ & $26.5 \pm 6.3$ \\
\hline \multicolumn{3}{|l|}{ Distribution — no. (\%) } \\
\hline$<30$ & $1589(76)$ & $1589(77)$ \\
\hline$\geq 30$ & $490(24)$ & $485(23)$ \\
\hline \multicolumn{3}{|l|}{ Race - no. (\%) } \\
\hline White & $1714(82)$ & $1742(84)$ \\
\hline Black & $84(4)$ & $79(4)$ \\
\hline South Asian & $114(5)$ & $102(5)$ \\
\hline Other & $167(8)$ & $151(7)$ \\
\hline \multicolumn{3}{|l|}{ Pregnancy history } \\
\hline Nulliparous - no. (\%) & $474(23)$ & $514(25)$ \\
\hline Previous preterm births at $\geq 24 \mathrm{wk}$ to $<34 \mathrm{wk}-$ no. (\%) & $83(4)$ & $90(4)$ \\
\hline \multicolumn{3}{|l|}{ Previous miscarriages at <24 wk of gestation - no. (\%) } \\
\hline 0 & $1145(55)$ & $1157(56)$ \\
\hline 1 or 2 & $792(38)$ & $758(37)$ \\
\hline$\geq 3$ & $142(7)$ & $159(8)$ \\
\hline No. of previous miscarriages — median (IQR) & $0(0-1)$ & $0(0-1)$ \\
\hline \multicolumn{3}{|l|}{ Amount of bleeding as assessed by PBAC scoret' - no. (\%) } \\
\hline$\leq 2$ & $1913(92)$ & $1907(92)$ \\
\hline$\geq 3$ & $166(8)$ & $167(8)$ \\
\hline Fetal heart activity at presentation — no. (\%) † & $1710(82)$ & $1701(82)$ \\
\hline \multicolumn{3}{|c|}{$\begin{array}{l}\text { Plus-minus values are means } \pm \text { SD. There were no significant differences between the two groups in the characteristics } \\
\text { listed. Further details regarding baseline characteristics are provided in Table S1 in the Supplementary Appendix. Per- } \\
\text { centages may not sum to } 100 \text { because of rounding. IQR denotes interquartile range. } \\
\text { This variable was a minimization variable. } \\
\text { Race was reported by the participant. } \\
\text { Pictorial blood-loss assessment chart (PBAC) scores range from } 1 \text { to } 4 \text {, with higher scores indicating greater vaginal } \\
\text { blood loss. } \\
\text { If }\end{array}$} \\
\hline
\end{tabular}

1 showed differential effects of progesterone: the effect of progesterone in women with bleeding in early pregnancy differed according to the number of previous miscarriages, with a suggestion of benefit among women who had had three or more previous miscarriages. Previous reports have indicated a steep and proportionate increase in the loss of chromosomally normal pregnancies (i.e., euploid miscarriages) with increasing number of previous miscarriages. ${ }^{15}$ Given that the potential benefit of progesterone therapy would be expected to be specific to euploid pregnancies, an increasing level of benefit in women with increasing number of previous 
Table 2. Primary Outcome and Secondary Outcomes.*

\begin{tabular}{|c|c|c|c|}
\hline Outcome & $\begin{array}{l}\text { Progesterone } \\
(\mathrm{N}=\mathbf{2 0 2 5})\end{array}$ & $\begin{array}{l}\text { Placebo } \\
(\mathrm{N}=2013)\end{array}$ & $\begin{array}{l}\text { Relative Rate or } \\
\text { Mean Difference } \\
(95 \% \mathrm{Cl}) 广\end{array}$ \\
\hline \multicolumn{4}{|l|}{ Primary outcome - no. (\%) } \\
\hline Live birth at $\geq 34 \mathrm{wk}$ & $1513(75)$ & $1459(72)$ & 1.03 (1.00 to 1.07$) \div$ \\
\hline \multicolumn{4}{|l|}{ Secondary maternal outcomes - no. (\%)』 } \\
\hline Ongoing pregnancy at $12 \mathrm{wk}$ & $1672(83)$ & $1602(80)$ & 1.04 (1.01 to 1.07$)$ \\
\hline Miscarriage, defined as loss of pregnancy at $<24 \mathrm{wk} \emptyset$ & $410(20)$ & $451(22)$ & 0.91 (0.81 to 1.01$)$ \\
\hline Live birth at $<34 \mathrm{wk}$ & $68(3)$ & $64(3)$ & 1.06 (0.76 to 1.49$)$ \\
\hline Ectopic pregnancy & 0 & $2(<1)$ & - \\
\hline Stillbirth, defined as intrauterine death at $\geq 24 \mathrm{wk}$ & $5(<1)$ & $6(<1)$ & $0.82(0.25$ to 2.66$)$ \\
\hline Termination of pregnancy\| & $34(2)$ & $36(2)$ & 0.94 (0.59 to 1.50$)$ \\
\hline \multicolumn{4}{|l|}{$\begin{array}{l}\text { Secondary neonatal outcomes among women with live } \\
\text { births at } \geq 24 \mathrm{wk} \mathbb{}\end{array}$} \\
\hline \multicolumn{4}{|l|}{ Gestational age at delivery*** } \\
\hline Wk of gestation & $\begin{array}{c}38 \text { wk } 4 \text { days } \pm 2 \text { wk } \\
4 \text { days }\end{array}$ & $\begin{array}{c}38 \text { wk } 4 \text { days } \pm 2 \text { wk } \\
3 \text { days }\end{array}$ & $\begin{array}{l}0.11 \text { days }(-0 \text { wk } 1 \text { day } \\
\text { to } 0 \text { wk } 2 \text { days }) \dagger\end{array}$ \\
\hline No. of women & 1581 & 1521 & \\
\hline \multicolumn{4}{|l|}{ Birth weight †† } \\
\hline Mean weight $-\mathrm{g}$ & $3242 \pm 656$ & $3261 \pm 659$ & $-21(-67$ to 25$) \dagger$ \\
\hline No. of infants & 1604 & 1539 & \\
\hline Death at 28 days of neonatal life - no./total no. (\%) & $8 / 1605(<1)$ & $2 / 1533(<1)$ & $3.84(0.80$ to 18.40$) \dagger$ \\
\hline
\end{tabular}

* Plus-minus values are means \pm SD. Additional data on outcomes are provided in Table S2 in the Supplementary Appendix.

$\dagger$ Relative rates are shown for the primary outcome, all secondary maternal outcomes, and the secondary neonatal outcome of death at 28 days of neonatal life. The mean difference is shown for the secondary neonatal outcomes of gestational age at delivery and birth weight. For binary outcomes, a relative rate of less than 1 favors the progesterone group, except for live birth after at least 34 weeks of gestation and ongoing pregnancy at 12 weeks, for which a relative rate greater than 1 would favor progesterone. For continuous outcomes, a mean difference of less than 0 favors the progesterone group. The widths of the confidence intervals were not adjusted for multiplicity, so the intervals should not be used to infer definitive treatment effects.

$+\mathrm{P}=0.08$.

I Five women in the progesterone group and three women in the placebo group had both a live birth after at least 34 weeks of gestation and a miscarriage; one woman in the placebo group had both a termination of pregnancy and a miscarriage; and one woman in the placebo group had both a live birth before 34 weeks and a stillbirth.

I The median gestational age was 8 weeks (interquartile range, 7 to 10) in both trial groups.

|| The reasons for termination of pregnancy in the progesterone group were social for 13 women and medical for 21 women. The reasons for termination of pregnancy in the placebo group were social for 12 women and medical for 24 women. The median gestational age was 14 weeks (interquartile range, 12 to 19 ) in the progesterone group and 15 weeks (interquartile range, 11 to 18 ) in the placebo group.

$* *$ The gestational age at delivery was unknown for the infants of two women in the placebo group.

$\dagger \uparrow$ The birth weight was unknown for the infants of 6 women in the progesterone group and 6 women in the placebo group.

The neonatal vital status at 28 days of life was unknown for 17 women ( 5 in the progesterone group and 12 in the placebo group).

miscarriages is consistent with our understanding of the biologic factors associated with risk of miscarriage. A history of miscarriage is one of only two stratification or prognostic risk factors (the other being maternal age) cited in the 2017 guideline of the European Society of Human Reproduction and Embryology on recurrent pregnancy loss as being useful for identifying highrisk patients. ${ }^{16}$ However, we did not identify this subgroup as one of special interest a priori in our statistical analysis plan, ${ }^{17}$ and multiple comparisons were performed (without adjustment for multiplicity); thus, this observation requires validation.

Some limitations of our trial should be considered. First, we studied a vaginal preparation of progesterone, at a dose of $400 \mathrm{mg}$ twice daily, and it is possible that the results observed with this regimen are not generalizable to women receiving other doses and preparations by other 


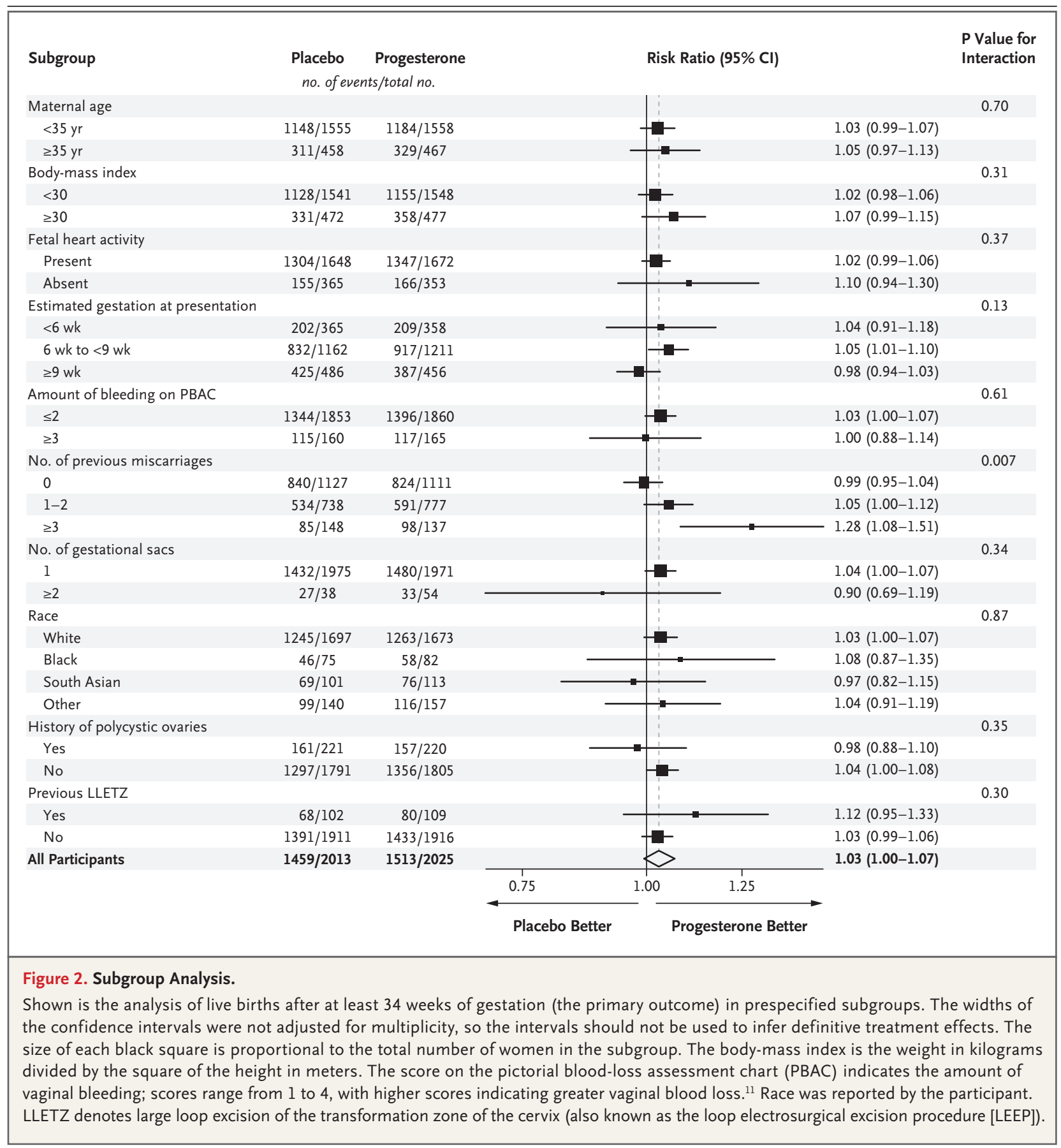

routes. Micronized vaginal progesterone has an identical molecular structure to natural progesterone, whereas other formulations of progestational agents have a different molecular structure and therefore potentially different mechanisms of action and pharmacologic features. Immunomodulatory effects of progesterone at the tropho- blastic-decidual interface have been proposed as a mechanism whereby progesterone might prevent miscarriage. ${ }^{18}$ The vaginal route delivers a greater proportion of drug to the relevant site (i.e., the uterus) with the use of the "first uterine pass" effect. ${ }^{19,20}$ Furthermore, trials that have evaluated vaginal progesterone in the prevention 
of preterm birth have shown its effectiveness when administered by this route. ${ }^{21,22}$

Second, we started progesterone treatment only in women who had an intrauterine sac; therefore, our trial cannot provide evidence on the effects of earlier use of progesterone, before a pregnancy sac is visible on an ultrasound examination. Third, the participants discontinued progesterone at 16 weeks of gestation; however, we consider it to be unlikely that therapy beyond this time would have affected the outcomes related to miscarriage. Finally, although we found no increase in the risk of congenital abnormalities among babies of women treated with progesterone, the trial was not powered for such rare outcomes.

In conclusion, treatment with progesterone did not result in significant improvement in the incidence of live births among women with vaginal bleeding during the first 12 weeks of pregnancy.

This article presents independent research commissioned by the National Institute for Health Research (NIHR). A monograph reporting the data collected in this trial is planned for publication in the NIHR Journals Library. Further information is available at www.journalslibrary.nihr.ac.uk/htal. The views and opinions expressed by the authors in this publication are those of the authors and do not necessarily reflect those of the National Health Service, the NIHR, the Medical Research Council, the NIHR Central Commissioning Facility, the NIHR Evaluation, Trials and Studies Coordinating Centre, the NIHR Health Technology Assessment program, or the Department of Health.

A data sharing statement provided by the authors is available with the full text of this article at NEJM.org.

Supported by the United Kingdom NIHR Health Technology Assessment program (project number HTA 12/167/26).

Dr. Lumsden reports receiving advisory fees from PregLem; and Dr. Norman, receiving consulting fees, paid to the University of Edinburgh, from Dilafor and GlaxoSmithKline. No other potential conflict of interest relevant to this article was reported.

Disclosure forms provided by the authors are available with the full text of this article at NEJM.org.

We thank the women who participated in this trial; the investigators for supervising recruitment and randomization at the trial centers (Mr. Samson Agwu, Mrs. Rita Arya, Miss Miriam Baumgarten, Dr. Catey Bass, Miss Sumita Bhuiya, Prof. Tom Bourne, Mr. James Clark, Mr. Samual Eckford, Mr. Zeiad ElGizawy, Mrs. Joanne Fletcher, Miss Preeti Gandhi, Dr. Mary Gbegaje, Dr. Ingrid Granne, Mr. Mamdough Guirguis, Dr. Pratima Gupta, Dr. Hadi Haerizadeh, Dr. Laura Hipple, Mr. Piotr Lesny, Miss Hema Nosib, Mr. Jonathan Pepper, Mr. Jag Samra, Ms. Jayne Shillito, Dr. Rekha Shrestha, Dr. Jayasree Srinivasan, Dr. Ayman Swidan, and Prof. Derek Tuffnell); the PRISM research nurses who assisted in the collection of data; Leanne Beeson, Mary Nulty, and Louisa Edwards for their support in managing and coordinating the trial; Prof. Siladitya Bhattacharya for chairing the trial steering committee; Prof. Andrew Shennan for chairing the data and safety monitoring committee; Dr. Javier Zamora and Dr. Willem Ankum for participating in the data and safety monitoring committee; and all those not otherwise mentioned above who have contributed to the PRISM trial.

\section{APPENDIX}

The authors' full names and academic degrees are as follows: Arri Coomarasamy, M.B., Ch.B., M.D., F.R.C.O.G., Adam J. Devall, B.Med.Sci., Ph.D., Versha Cheed, M.Sc., Hoda Harb, M.B., Ch.B., Ph.D., Lee J. Middleton, B.Sc., Ioannis D. Gallos, D.M.S., M.D., Helen Williams, B.Sc., Abey K. Eapen, M.D., Ph.D., Tracy Roberts, Ph.D., R.G.N., Chriscasimir C. Ogwulu, Ph.D., Ilias Goranitis, Ph.D., Jane P. Daniels, M.Med.Sci., Ph.D., Amna Ahmed, M.B., B.S., M.R.C.O.G., Ruth Bender-Atik, B.A., Kalsang Bhatia, M.B., B.S., F.R.C.O.G., Cecilia Bottomley, DM.B.B.Chir., M.R.C.O.G., M.D., Jane Brewin, B.A., Meenakshi Choudhary, M.B., B.S., M.D., M.R.C.O.G., Ph.D., Fiona Crosfill, M.B., B.S., M.R.C.O.G., Dip.Med.Ed., Shilpa Deb, M.B., B.S., M.R.C.O.G., D.G.O., Ph.D., W. Colin Duncan, M.B., Ch.B., M.D., F.R.C.O.G., Andrew Ewer, M.B., Ch.B., M.D., M.R.C.P., F.R.C.P.C.H., Kim Hinshaw, M.B., B.S., F.R.C.O.G., Tom Holland, M.B., B.S., M.R.C.O.G., M.D., Feras Izzat, M.B., Ch.B., M.R.C.O.G., Jemma Johns, M.B., B.S., M.R.C.O.G., M.D., Kathiuska Kriedt, M.B., B.S., Mary-Ann Lumsden, M.B., B.S., M.D., F.R.C.O.G., Padma Manda, M.B., B.S., D.G.O., D.F.F.P., F.R.C.O.G., Jane E. Norman, M.B., Ch.B., M.D., F.R.C.O.G., F. Med.Sci., F.R.C.P. Edin., Natalie Nunes, M.B., B.S., M.R.C.O.G., M.D. (Res.), Caroline E. Overton, M.B., B.S., M.D., M.R.C.O.G., F.H.E.A., F.R.C.O.G., Siobhan Quenby, B.Sc., M.B., B.S., M.R.C.O.G., C.C.S.T., M.D., F.R.C.O.G., Sandhya Rao, M.B., B.S., M.D., M.R.C.O.G., Jackie Ross, M.B., B.S., F.R.C.O.G., C.C.S.T., Anupama Shahid, M.B., B.S., D.F.S.R.H., M.R.C.O.G., Martyn Underwood, M.B., Ch.B., M.R.C.O.G., Nirmala Vaithilingam, M.D., Linda Watkins, M.B., Ch.B., M.R.C.O.G., D.F.F.P., Catherine Wykes, M.B., B.S., M.R.C.O.G., M.A., Andrew Horne, M.B., Ch.B., M.R.C.O.G., Ph.D., F.R.C.O.G., and Davor Jurkovic, M.B., B.S., M.D., M.R.C.O.G.

The authors' affiliations are as follows: Tommy's National Centre for Miscarriage Research, College of Medical and Dental Sciences, University of Birmingham, Birmingham (A.C., A.J.D., V.C., H.H., L.J.M., I.D.G., H.W., A.K.E., T.R., C.C.O.), the Faculty of Medicine and Health Sciences, University of Nottingham (J.P.D.), and Nottingham University Hospitals NHS Trust (S.D.), Nottingham, City Hospitals Sunderland NHS Foundation Trust, Sunderland (A.A., K.H.), the Miscarriage Association, Wakefield (R.B.A.), East Lancashire Hospitals NHS Trust, Burnley (K.B.), Tommy's Charity (J.B.), Guy's and St. Thomas' NHS Foundation Trust (T.H.), King's College Hospital NHS Foundation Trust (J.J., J.R.), University College London Hospitals NHS Foundation Trust (K.K., D.J.), West Middlesex Hospital, Chelsea and Westminster NHS Foundation Trust (N.N., C.B.), and Barts and the London NHS Trust (A.S.), London, Newcastle upon Tyne Hospitals NHS Foundation Trust, Newcastle (M.C.), Lancashire Teaching Hospitals NHS Foundation Trust, Preston (F.C.), the MRC Centre for Reproductive Health, University of Edinburgh, Edinburgh (W.C.D., J.E.N., A.W.H.), Liverpool Women's NHS Foundation Trust (L.W.) and St. Helens and Knowsley NHS Trust (S.R.), Liverpool, University Hospitals Coventry and Warwickshire NHS Trust, Coventry (F.I.), the Department of Medicine, University of Glasgow, Glasgow (M.-A.L.), South Tees Hospitals NHS Foundation Trust, Middlesbrough (P.M.), University Hospitals Bristol NHS Foundation Trust, Bristol (C.E.O.), the Biomedical Research Unit in Reproductive Health, University of Warwick, Warwick (S.Q.), Shrewsbury and Telford NHS Trust, Telford (M.U.), Portsmouth Hospitals NHS Trust, Portsmouth (N.V.), and Surrey and Sussex Healthcare NHS Trust, Redhill (C.W.) - all in the United Kingdom; the Melbourne School of Population and Global Health, University of Melbourne, Melbourne, VIC, Australia (I.G.); and the Carver College of Medicine, University of Iowa Health Care, Iowa City (A.E.). 
REFERENCES

1. Everett C. Incidence and outcome of bleeding before the 20th week of pregnancy: prospective study from general practice. BMJ 1997;315:32-4.

2. Cantwell R, Clutton-Brock T, Cooper $\mathrm{G}$, et al. Saving mothers' lives: reviewing maternal deaths to make motherhood safer: 2006-2008 - the eighth report of the Confidential Enquiries into Maternal Deaths in the United Kingdom. BJOG 2011;118:Suppl 1:1-203.

3. Murphy FA, Lipp A, Powles DL. Followup for improving psychological well being for women after a miscarriage. Cochrane Database Syst Rev 2012;3:CD008679.

4. Farren J, Jalmbrant M, Ameye L, et al. Post-traumatic stress, anxiety and depression following miscarriage or ectopic pregnancy: a prospective cohort study. BMJ Open 2016;6(11):e011864.

5. Malassiné A, Frendo JL, Evain-Brion D. A comparison of placental development and endocrine functions between the human and mouse model. Hum Reprod Update 2003;9:531-9.

6. Wahabi HA, Fayed AA, Esmaeil SA, Bahkali KH. Progestogen for treating threatened miscarriage. Cochrane Database Syst Rev 2018;8:CD005943.

7. Coomarasamy A, Williams H, Truchanowicz E, et al. A randomized trial of progesterone in women with recurrent miscarriages. N Engl J Med 2015;373:2141-8. 8. Haas DM, Hathaway TJ, Ramsey PS. Progestogen for preventing miscarriage in women with recurrent miscarriage of unclear etiology. Cochrane Database Syst Rev 2018;10:CD003511.
9. American College of Obstetricians and Gynecologists. ACOG practice bulletin - clinical management guidelines for obstetricians-gynecologists: early pregnancy loss. May 2015 (https://www.acog.org/ -/media/Practice-Bulletins/Committee-on -Practice-Bulletins----Gynecology/Public/ pb150.pdf).

10. Practice Committee of the American Society for Reproductive Medicine. Evaluation and treatment of recurrent pregnancy loss: a committee opinion. Fertil Steril 2012;98:1103-11.

11. Bottomley C, Van Belle V, Pexsters A, et al. A model and scoring system to predict outcome of intrauterine pregnancies of uncertain viability. Ultrasound Obstet Gynecol 2011;37:588-95.

12. White IR, Horton NJ, Carpenter J, Pocock SJ. Strategy for intention to treat analysis in randomised trials with missing outcome data. BMJ 2011;342:d40.

13. Zou G. A modified Poisson regression approach to prospective studies with binary data. Am J Epidemiol 2004;159: 702-6.

14. Peto R, Pike MC, Armitage $\mathrm{P}$, et al Design and analysis of randomized clinical trials requiring prolonged observation of each patient. I. Introduction and design. Br J Cancer 1976;34:585-612. 15. Ogasawara M, Aoki K, Okada S, Suzumori K. Embryonic karyotype of abortuses in relation to the number of previous miscarriages. Fertil Steril 2000;73. 300-4.

16. ESHRE Early Pregnancy Guideline Development Group. Recurrent pregnancy loss: guideline of the European Society of Human Reproduction and Embryology. November 2017 (https://www.eshre.eu/ Guidelines-and-Legal/Guidelines/Recurrent -pregnancy-loss).

17. Wang R, Lagakos SW, Ware JH, Hunter DJ, Drazen JM. Statistics in medicine reporting of subgroup analyses in clinical trials. N Engl J Med 2007;357:2189-94.

18. Robinson DP, Klein SL. Pregnancy and pregnancy-associated hormones alter immune responses and disease pathogenesis. Horm Behav 2012;62:263-71.

19. Bulletti C, de Ziegler D, Flamigni C, et al. Targeted drug delivery in gynaecology: the first uterine pass effect. Hum Reprod 1997;12:1073-9.

20. Cicinelli E, Cignarelli M, Sabatelli S, et al. Plasma concentrations of progesterone are higher in the uterine artery than in the radial artery after vaginal administration of micronized progesterone in an oil-based solution to postmenopausal women. Fertil Steril 1998;69: 471-3.

21. Fonseca EB, Celik E, Parra M, Singh M, Nicolaides KH. Progesterone and the risk of preterm birth among women with a short cervix. N Engl J Med 2007;357: 462-9.

22. Romero R, Conde-Agudelo A, Da Fonseca $\mathrm{E}$, et al. Vaginal progesterone for preventing preterm birth and adverse perinatal outcomes in singleton gestations with a short cervix: a meta-analysis of individual patient data. Am J Obstet Gynecol 2018;218:161-80.

Copyright (c) 2019 Massachusetts Medical Society. 